\title{
A PROSTITUIÇÃO E A DIGNIDADE DA PESSOA HUMANA: CRÍTICA LITERÁRIA E MUSICAL À NEGAÇÃO DO DIREITO FUNDAMENTAL AO TRABALHO

\author{
THE PROSTITUTION AND THE PERSON DIGNITY: LITERARY AND MUSICAL CRITICISM TO THE \\ FAILURE OF FUNDAMENTAL RIGHT TO WORK
}

Bárbara Natália Lages Lobo* José Adercio Leite Sampaio**

Resumo: No presente artigo antecede-se pesquisa densa acerca do "submundo" da prostituição, sob a óptica dos direitos fundamentais e a sua concreção. Analisou-se a relativização da dignidade humana pela negação do direito ao trabalho àquelas pessoas que se prostituem, bem como a sua condição de invisibilidade e mazela social. Destacou-se, ainda, por meio da análise dos direitos sexuais, que envolvem a liberdade, a indissolubilidade do "amálgama normativo" direito, moral e religião, demonstrando, assim, a necessidade premente de regulação da atividade como forma de se destinar aos prostitutos igual respeito e consideração.

Palavras-chave: Prostituição. Direitos fundamentais. Dignidade da pessoa humana. Moralidade. Direito ao trabalho.
Résumé: Le présent article précède une recherche dense à propos du "sous-monde" de la prostitution, dans l'optique des droits fondamentaux et de leur concrétisation. La relativisation de la dignité humaine - par la négation du droit au travail des personnes qui se prostituent - a été analysée, tout comme leur condition d'invisibilité et de misère sociale. Est aussi mise en avant 1'indissolubilité de "l'amalgame normatif" droit, morale et religion, au moyen de l'analyse des droits sexuels qui impliquent la liberté, démontrant ainsi la nécessité pressante d'une régulation de l'activité comme forme $d^{\prime}$ 'accorder un égal respect et une considération, pour les prostitués.

Mots-clés: Prostitution. Droits fondamentaux. Dignité humaine. Morale. Droit au travail.

\footnotetext{
" Mestre em Direito pela Pontifícia Universidade Católica de Minas Gerais; doutoranda em Direito pela Pontifícia Universidade Católica de Minas Gerais; Professora de graduação e pós-graduação na Pontifícia Universidade Católica de Minas Gerais; Servidora pública no Tribunal Regional do Trabalho da $3^{a}$ Região; Av. Dom José Gaspar, 500, prédio 5, $2^{\circ}$ andar, sala 217 , Coração Eucarístico, 30535-901; Belo Horizonte, Minas Gerais, Brasil; barbaralobo@hotmail.com

"Doutor e Mestre em Direito pela Pontifícia Universidade Católica de Minas Gerais; Professor de graduação e pós-graduação na Pontifícia Universidade Católica de Minas Gerais e na Escola Superior Dom Helder Câmara; Procurador da República; Avenida Brasil, 1877, Funcionários, 30140-002, Belo Horizonte, Minas Gerais, Brasil; joseadercio@terra.com.br
} 


\section{Introdução}

De tudo que é nego torto/do mangue e do cais do porto/ Ela já foi namorada/ O seu corpo é dos errantes/ Dos cegos, dos retirantes/É de quem não tem mais nada. Dá-se assim desde menina/ Na garagem, na cantina/ Atrás do tanque, no mato/ É a rainha dos detentos/ Das loucas, dos lazarentos/ Dos moleques do internato. (BUARQUE, 1978).

E é dessa forma que se pretende abordar o tema deste artigo "Prostituição e (in)dignidade humana" para que a densidade do "submundo" se transforme em leveza. O amor pelo Direito, pela Literatura e pela Música dará a tônica do que ora se escreve com o intuito de investigar a efetividade e a crise dos direitos fundamentais. Buscar a significação de "efetividade" é relativamente tranquilo, no sentido de se entender aqui como concreção, correspondência entre a realidade e a ordem jurídica. Contudo, o vocábulo "crise" se apresenta sensível pela multiplicidade de significados. ${ }^{2}$

A fonte significante que ora se elege é a Psicologia para que se reflita sobre "crise" como um momento de transição e, como tal, de reflexão, que poderá trazer consigo "perdas necessárias".

A tarefa da transição, no desenvolvimento, consiste em pôr fim a um tempo da vida; aceitar as perdas que esse término implica; rever e avaliar novamente o passado; resolver quais os aspectos do passado que devem ser mantidos, quais devem ser rejeitados; e considerar os desejos e as possibilidades para o futuro. $\mathrm{O}$ indivíduo está suspenso entre o passado e o futuro, lutando para transpor a distância que os separa. Muita coisa do passado deve ser abandonada - separada, cortada da vida da pessoa, rejeitada com raiva, repudiada com tristeza e pena. E muita coisa pode ser usada como base para o futuro. Mudanças devem ser tentadas, quer no eu, quer no mundo. (LEVINSON apud VIORST, 2005, p. 272).

O motivo da eleição do significado do termo pelo viés psicológico é pessoal, nada melhor do que a própria vivência para que se consiga colocar "verdade" naquilo que se faz: "[...] meu delírio é a experiência com coisas reais [...]" (BELCHIOR, 1989). Nesse momento de crise existencial, no

\footnotetext{
1 Neste momento é importante confessar que a palavra "submundo" é usada de maneira proposital para a provocação de repugnância, pois, é associável à palavra imundo (de mesmo sufixo) como algo que não pertence ao nosso ambiente. A palavra tem tom idiossincrático capaz de expressar visão e cheiro repugnáveis daqueles que vivem em situação de marginalidade social. Porém, outra significação é possível: o prefixo "sub" utilizado como aquilo que está embaixo, suportando todo o peso daquilo que está em cima. Se concebermos dessa forma, poderemos visualizar o esmagamento dos incluídos sobre os excluídos.

2 O professor Sampaio (2006, p. 9, grifo do autor) já associou o nome "crise" ao "demo", e não deixa de ser. A sua origem "inexorcisável" é assim apresentada: "Crise tem uma origem para lá de curiosa. Vem do avô do grego, Krino, que significa, olha o estranho: julgar ou separar. Krisis ou Kr...sij, sua mãe, indica mais precisamente a 'hora certa de julgar e separar' ou, para não ser acusado de sexista, o 'momento de decisão' ou 'de separação'. O que tem de prosaico nessa etimologia é que na auto-ajuda (alter-ajuda?) multiplica-se a afirmação de que a crise é sinônima de oportunidade. Não se complementa, talvez por otimismo, que há pelo menos duas possibilidades nesses instantes: de superar ou ser superado, de vencer ou fracassar. A unilateralidade do sentido, talvez sequer avaliado pelos especialistas no assunto, cegos pelo otimismo, tem raízes na filosofia de Parmênides, que a definia como a decisão fundamental da existência de 'ser ou não ser'. Não será a famosa interrogação hamletiana, dualista? Em Parmênides, não, pela necessidade absoluta de o 'ser' ser. Não havia a liberdade para não ser. Isso porque o "ser" era decorrência da crise ou do julgamento pela razão (logos); o 'não-ser' era a indecisão, a ausência da crise ou o nada. Sem embargo, o 'ser' só seria se houvesse oposto, o 'não-ser', o que deixava Parmênides em maus lençóis. Fosse como fosse, a crise (distinção) ontológica germinava no pensamento ocidental e seria logo rediscutida em Platão (o sensível e o supra-sensível) e em Aristóteles (a física e a metafísica), ambos a preferir kri...sij mais no sentido de julgamento. Em Platão, para ficarmos no exemplo, enfatiza-se a "crise" depois da morte ou na transmigração da alma [...] segundo o estado do homem e sua decisão (crise) por justiça, a ocupar o reino da eternidade e do celestial, ou da injustiça, moradora do reino terreno e mortificável."
} 
qual, afirma-se com segurança sobre as necessidades de transformação que esses períodos "críticos" trazem consigo: "[...] amar e mudar as coisas me interessa mais." (BELCHIOR, 1989).

A esperança idealista de um mundo igualitário movimenta a crise dos direitos fundamentais, e a transformação que daí deve ser decorrente se refere à efetividade desses direitos. Apresenta-se, assim, o liame entre os termos. Contudo, a busca por aquilo que se deve abandonar para que esse período de "metamorfose constitucional" seja exitoso será objeto de intenso estudo e debate, por ora, introdutório.

Diante da ausência de regulação do trabalho das pessoas que se prostituem, ${ }^{3}$ pergunta-se se a dignidade da pessoa humana é absoluta, quais são seus fundamentos (morais, religiosos e/ou jurídicos), bem como o motivo de o Direito Brasileiro relativizar a dignidade da pessoa humana não conferindo igual consideração e respeito aos profissionais do sexo, em razão da opressão sexual e da domesticação religiosa, sob o temor do estigma de "País da Libidinagem", e qual seria a melhor maneira possível para o reconhecimento da atividade de prostituição como trabalho formal e regulação do seu exercício, sob a óptica constitucional. É o que se passa a analisar.

\section{Dignidade da pessoa humana ${ }^{4}$}

A dignidade da pessoa humana é alçada pelo direito contemporâneo como o centro de suas atenções, comportando várias definições possíveis, podendo ser percebida em diversos aspectos. Dignidade se origina na palavra latina decus, a significar ornamento, distinção, honra, glória. Decet

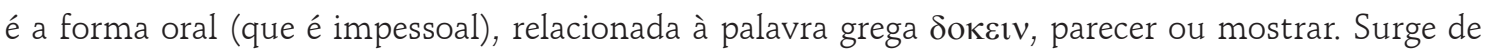
decer o termo dignitas, relacionado, por sua vez, ao grego $\alpha \chi \imath \mu \alpha$ e indica, nas duas matrizes, algo autoevidente (que se ostenta) e que deve ser respeitado pela autoridade constituída. Formalmente, remete-se a um axioma, a algo ensinado a ser o primeiro ou o mais alto valor.

As acepções da expressão, ainda hoje, podem ser associadas à função da natureza superior do homem em face dos outros seres (CICERO, 1913, p. 209; MCCRUDDEN, 2008, p. 656), à teologia da imagem e semelhança da criatura ao Criador e a Cristo ou dignitas conditionis humanae, do que se extrai a singularidade de cada ser (AQUINAS, 1978), ${ }^{5}$ a atributo da razão que impõe o ser humano como fim em si mesmo (KANT, 1997, p. 18, 42; KANT, 2014, p. 35-36, 101; RACHELS, 1986, p. 114, 126-127). A atributividade pode ser feita, na filiação kantiana, à ontologia do ser humano, pelo fato tão somente de sua existência (teoria da dotação); para outros, ele é o resultado da ação e da subjetividade humanas, em face das dificuldades graves para justificar a discriminação entre os seres humanos (teoria do desempenho) (VIOLA, 2008, p. 102). A primeira não diferencia ser e ação,

\footnotetext{
3 Não se pretende restringir a análise às prostitutas, muito embora, em vários momentos será esse o termo utilizado, pois a presente pesquisa não se delimita às mulheres. Trabalha-se com todas as pessoas que se prostituem (mulheres, homens e travestis), portanto, dar-se-á preferência pela utilização de termos que as abranjam, como prostituídos, prostitutos e pessoas que se prostituem.

4 Toma-se o binômio "pessoa humana" como forma de revelação e ênfase de que a história política e do direito nem sempre considerou a sinonímia entre "pessoa" e "ser humano". Mesmo hoje se os termos do binômio estão formalmente associados em significados, na prática, como revelamos no artigo, ainda há uma dissociação, pelo menos, parcial.

5 Veja-se, ainda hoje, entre outros: Schooyans (1991, p. 495-511).
} 
o ser é moralmente agente merecedor de dignidade. A outra lembra as virtudes heroicas, a nobreza e a magnanimidade, que seguem de Aristóteles a Descartes. Todavia, reconhece as razões pelas quais alguns homens são particularmente dignos de serem honrados e mudam com o tempo e valores.

Em Hobbes (2002, p. 63), "[...] o valor ou mérito de um homem, é, como em todas as outras coisas, o seu preço, ou seja, o que se deveria fazer para o uso do próprio poder. Não se trata de uma coisa absoluta, mas dependente da necessidade e do julgamento dos outros." Já foi a honra e, com as revoluções burguesas, tornou-se a riqueza e, depois, o trabalho. Trata-se de uma noção construída com base no reconhecimento social da pessoa (LUHMANN, 2002). As duas acepções não são inconciliáveis, até porque os seres humanos são produtos inacabados. Embora portadores de nascimento, estão sempre em processo de autorrealização por causa de sua liberdade original. Cuida-se de uma dotação originária que comporta um dever, uma tarefa e uma conquista de realização (MIRANDOLA, 1965). Um expediente de sacralidade envolvido pela historicidade social e pela vulnerabilidade que acomete a todos, seres finitos e mortais, mas, especialmente, aos socialmente excluídos (MARCEL, 1964, p. 168).

A bidimensionabilidade do princípio se projeta a realizar a sua pluriteleologia ou multifuncionalidade, designadamente como tarefas:

a) legitimadora - da ordem constitucional e das práticas sociais, políticas e jurídicas (BACKER, 2009, p. 115);

b) ordenadora - dos poderes públicos e privados, de modo a promover a dignidade individual e de todos (MURPHY, 1980, p. 758);

c) temporal - de ideia que assegura a estabilidade das instituições democráticas e da Constituição, embora possam variar seu alcance e expressão, sua fortaleza e fragilidade (MCCRUDDEN, 2008, p. 723);

d) essencial - de barreira a um conteúdo mínimo de qualidade de vida, autonomia e igualdade;

e) integradora - da multiplicidade dos processos identitários que conduzem as visões de mundo plurais à convivência constitucional;

f) limitadora - da atuação arbitrária ou discriminatória do Estado;

g) libertária ou emancipatória - a prover a ampliação e a efetividade da autonomia e igualdade, concebendo-a como matriz dos direitos e de sua efetuação por meio da participação nos processos deliberativos, nos ônus e benefícios sociais (dignidade também como status activus processualis) (LANDA, 2002).

Não se pode reduzi-la, portanto, a uma função meramente liberal (dignidade como limite do poder ou ordenação do direito), política (dignidade como integração) ou social (dignidade como igualdade e emancipação), pois ela se expressa na pluralidade de vozes.

A concepção da dignidade da pessoa humana que mais tem assentimento parece mesmo ser a apresentada por Kant, definida no ser humano como um fim em si mesmo, e não como meio 
ou coisa. Essa concepção é desenvolvida em várias concepções não apenas de vida justa (dignidade como direitos individuais), mas também de vida boa (dignidade como política do bem comum). É ela que faz pouco caso das fronteiras, raças ou etnias, definindo-se ora como um metavalor, ora como pressuposto de direitos, ora como direito ou princípio material de direitos, talvez por decorrer da necessidade universal dos seres humanos de reconhecimento e interesse do ser em ser respeitado.

Embora já presente em filosofia e em abordagens teológicas há muito tempo, a discussão jurídica acerca da realização da dignidade da pessoa humana é recente, ocupando mais as preocupações jusfilosóficas após a sua utilização na Declaração Universal dos Direitos Humanos em 1948. Seu predominante perfil liberal, desde então, passou a ser desafiado pela existência de grupos sociais oprimidos e marginalizados. Existência que nem sempre se expressava ou se expressa como reivindicação ou resistência, tanto por uma construção social de enclave de guetos ou isolamento social quanto pela autopercepção ou sentimento próprio de se constituir categoria humana ou social inferior, compositória de um "estorvo social" ou "limite do sistema". Estão entre esses os miseráveis, as "minorias", os imigrantes, os detentos e ex-detentos, os viciados em crack, as prostitutas.

A inclusão das pessoas que se prostituem como um desses grupos é inegável. Pratica-se contra essas pessoas um bloqueio social voluntário e involuntário que as mantêm em sua invisibilidade, no lugar marginal que lhes foi imposto. ${ }^{6}$ A dignidade aqui se apresenta, portanto, como um projeto de desvelação e de visualização política e jurídica dos invisíveis, seres humanos socialmente espectros de si mesmos, almas penadas em própria vida à procura de serem vistos e incluídos, não como homo sacer, para emprego da expressão de Agamben, mas como sujeitos plenos de direito.

\section{Prostituição e dignidade da pessoa humana}

A dignidade da pessoa humana dos profissionais do sexo é mitigada, em razão da situação de marginalidade social na qual são colocados historicamente, fundamentando-se essa discriminação na opressão moral e religiosa à prática de relações sexuais com o objetivo de se obter prazer ou dinheiro, em detrimento à finalidade procriatória, o que permanece mesmo após os avanços científicos que desenvolveram métodos contraceptivos. Não se está a reconhecer aqui que todas as pessoas que se prostituem o façam por prazer (embora existam aqueles que o façam), mas também pela necessidade do seu trabalho para a sua sobrevivência. Portanto, não se destinará grande atenção às razões

\footnotetext{
6 "Considerando os processos de 'feminização' e 'etnicização' da pobreza, há a necessidade de adoção, ao lado das políticas universalistas, de políticas específicas, capazes de dar visibilidade aos sujeitos de direito com maior grau de vulnerabilidade, visando ao pleno exercício do direito à inclusão social. Se o padrão de violação de direitos tem um efeito desproporcionalmente lesivo às mulheres e às populações afrodescendentes, adotar políticas 'neutras' no tocante ao gênero, à raça/etnia, significa perpetuar esse padrão de desigualdade e exclusão. Daí a urgência de toda forma de racismo; homofobia; xenofobia e outras formas de intolerância correlatas, tanto mediante a vertente repressiva (que proíbe e pune a discriminação e a intolerância) como mediante a vertente promocional (que promove a igualdade)." (PIOVESAN, 2008, p. 24). Recomenda-se a leitura da investigação das ações afirmativas no sentido de mitigar a discriminação racial, cujos resultados foram expostos na obra de Lobo (2013).
} 
pelas quais os prostituídos ingressaram nesse universo, quais foram os acontecimentos das suas vidas que os levaram a vender sexo, ${ }^{7}$ mas o que se pode fazer com a realidade que nos é apresentada. Maria Madalena, "de quem haviam saído sete demônios", conforme metáfora presente em Lucas 8:2 (BÍBLIA ON, 2014), é a prostituta mais conhecida do mundo (o que leva ao senso comum de ser a profissão "mais antiga" (BASSERMANN, 1994)), e origina-se na interpretação da passagem bíblica a exclusão social dessas pessoas. A mulher é apresentada como uma das pessoas mais importantes da vida de Jesus Cristo de forma magnífica pelo humor ácido de José Saramago em seu $O$ Evangelho Segundo Jesus Cristo: ${ }^{2}$

De certeza que a mulher ajoelhada se chama Maria, pois de antemão sabíamos que todas quantas aqui vieram juntar-se usam esse nome, apenas uma delas, por ser ademais Madalena, se distingue onomasticamente das outras, ora, qualquer observador, se conhecedor bastante dos factos elementares da vida, jurará, à primeira vista, que a mencionada Madalena é esta precisamente, porquanto só uma pessoa como ela, de dissoluto passado, teria ousado apresentar-se, na hora trágica, com um decote tão aberto, e um corpete de tal maneira justo que lhe faz subir e altear a redondez dos seios, razão por que, inevitavelmente, está atraindo e retendo a mirada sôfrega dos homens que passam, com grave dano das almas, assim arrastadas à perdição pelo infame corpo. É, porém, de compungida tristeza a expressão do seu rosto, e o abandono do corpo não exprime senão a dor de uma alma, é certo que escondida por carnes tentadoras, mas que é nosso dever ter em conta, falamos da alma, claro está, esta mulher poderia até estar inteiramente nua, se em tal preparo tivessem escolhido representá-la, que ainda assim haveríamos de demonstrar-lhe respeito e homenagem. (SARAMAGO, 1991, p. 15).

\section{O abandono do exercício do ofício como redenção é uma constante literária. Saramago} a aborda quando Maria, mãe de Jesus Cristo, abençoa-a com um abraço e um beijo, após ouvir a seguinte apresentação: "Sou Maria de Magdala e fui prostituta até conhecer o teu filho." (SARAMAGO, 1991, p. 344). Na literatura brasileira do século XIX, a redenção somente é possível após a morte

\footnotetext{
7 Traumas e desamparos, normalmente, motivam o exercício da atividade pelos prostituídos. Souza (2009, p. 175) analisa os sentimentos das prostitutas e relata: "O que há em comum na história de vida das mulheres entrevistadas é um tipo de socialização familiar disruptivo, que irá impedir a transmissão afetiva de valores como disciplina, autocontrole e pensamento prospectivo, num contexto familiar marcado pela ausência da figura paterna e pela presença de relações instrumentais de todo tipo, a começar pela frequência e naturalização de abusos sexuais sofridos na infância por essas mulheres. Além da carência, em qualquer medida significativa, de conhecimento resultante de um capital escolar incorporado, essas mulheres em sua infância nunca foram percebidas como 'um fim em si mesmas', como crianças com desejos, sentimentos, aspirações, medos e angústias que necessitavam de cuidado, proteção e afeto. Será a falta dessa 'segurança afetiva' que irá reproduzir um exército de 'perdedoras', sem qualquer chance na competição social por recursos escassos. Essa falta de uma 'economia emocional' marcada pelo autocontrole não produz apenas pessoas banidas da função de trabalhadoras úteis, que constitui a base do reconhecimento intersubjetivo da dignidade, mas também impossibilitadas de desenvolver uma dimensão expressiva de sua existência, para além dos clichês sociais, dos modelos sociais que chegam a elas como 'modelos prontos', prêt-à-porter."

8 José Saramago é o primeiro escritor da Língua Portuguesa a receber o Prêmio Nobel da Literatura, em 1998. A obra O Evangelho Segundo Jesus Cristo é emblemática, pois significa um ato de extrema coragem, pela forma explícita como tratou o concubinato de Jesus Cristo e Maria Madalena (a qual chamava Maria de Magdala - nome da cidade de origem da personagem). Segue trecho para deleite: "Este foi o primeiro sinal, doméstico, de interior, mas o segundo teve mais que se lhe diga porque representou um desafio frontal de Jesus à lei escrita e observada, acaso justificável, tendo em conta os comportamentos humanos normais, por viver Jesus com Maria de Magdala sem com ela estar casado, prostituta que havia sido, ainda por cima, por isso não se devia estranhar que estando uma mulher adúltera a ser apedrejada, conforme a lei de Moisés, e disso devendo morrer, aparecesses Jesus a interpor-se e a perguntar, Alto lá, quem de vós estiver sem pecado, seja o primeiro a lançar-lhe uma pedra, como se dissesse, Até eu, se não vivesse, como vivo, em concubinato, se estivesse limpo da lacra dos actos e pensamentos sujos, estaria convosco na execução dessa justiça." (SARAMAGO, 1991, p. 351). Sim! Saramago polemiza muito antes do Código da Vinci de Dan Brown. O escritor Dan Brown enreda o seu romance policial no suspense acerca da árvore genealógica da personagem Sophie Neveu, que seria descendente de Jesus Cristo e Maria Madalena, pertencente à sociedade Priorado de Sião.
} 
da prostituta Lucíola, narrada por José de Alencar $^{9}$ no romance que chocou a sociedade fluminense e brasileira da época.

A ideia de que a prostituição é um meio, trabalho provisório até que se consiga "sair dessa vida", reduz os profissionais a objetos, sendo-lhes negada a condição de "fim em si mesmo" preconizada pela dignidade da pessoa humana. É, portanto, necessária e plenamente possível uma adequação da legislação infraconstitucional ao direito à igualdade, à dignidade da pessoa humana, à livre iniciativa e ao direito ao exercício de qualquer trabalho, ofício ou profissão, regulando a atividade dos profissionais do sexo.

É necessária alguma sensibilidade no tratamento do tema, sobretudo diante da ausência de consenso quanto à identidade e até à autoidentidade entre trabalho e prostituição. Mesmo entre as prostitutas, o tema divide opiniões. Remete-se à autonegação da própria condição do trabalho que fazem à sua condição humana, espécie tributária da lógica hegeliana de senhor e escravo, e do preconceito com sua própria situação de ser profissional e de ser humano. É, portanto, problemática a tarefa de se pedir às prostitutas que não se consideram prostitutas para lutarem pelos direitos e pela própria causa (MÉIS, 2010, p. 248).

Até onde se parece mais clara a luta de reconhecimento e valorização de seu labor, ressurge disfarçado o espaço da autonegação do prostituto como ser digno de direitos. Um exemplo são as manifestações conhecidas como "Marcha das Vadias". Qual deve ser a acepção do termo "vadia" no imaginário de suas integrantes e na sociedade contemporânea? É preciso, portanto, considerar a persistência da cultura de exclusão ou de coisificação da atividade que realizam no processo e na possibilidade de autoafirmação feminina por meio da liberdade sexual e comportamental.

Poderíamos discutir o tema no âmbito da filosofia política, especialmente de viés marxiano, em busca de uma explicação para o fenômeno e até como crítica à proposta de reconhecimento da profissão do prostituto como atividade regulada (ou forma de apropriação privada do próprio ser). Embora sejam argumentos importantes, assim como a instrumentalização do corpo como forma de domínio da biopolítica, estamos alguns passos atrás em uma posição de direito a ter direitos. Sob as luzes do liberalismo e da economia capitalista, a centralidade do direito ao trabalho como dimensão de dignidade do ser humano ou como elemento desenvolvedor da sua personalidade requer, ao menos estrategicamente, que se lute pela afirmação da atividade da prostituta como trabalho. ${ }^{10}$

\footnotetext{
9 "A voz desfaleceu completamente, de extenuada que ela ficara por esse enérgico esforço. Eu chorava de bruços sobre o travesseiro, e as suas palavras suspiravam docemente em minha alma, como as dulias dos anjos devem ressoar aos espíritos celestes.

- Nunca te disse que te amava, Paulo!

- Mas eu sabia, e era feliz!

- Tu me purificaste ungindo-se com os teus lábios. Tu me santificaste com o teu primeiro olhar! Nesse momento Deus sorriu e o consórcio de nossas almas se fez no seio do Criador. Fui tua esposa no céu! E contudo essa palavra divina do amor, minha boca não a devia profanar, enquanto viva. Ela será meu último suspiro." (ALENCAR, 1999).

10 Como afirma Krieger (2012, p. 82): O direito fundamental ao trabalho aqui deve ser entendido como um direito de titularidade universal, que deve possuir eficácia interprivada, de que os indivíduos possam se realizar como pessoas através do trabalho, de alcançarem o binômio "contribuição e reconhecimento" por meio do trabalhar, desenvolvendo suas identidades; já o direito ao livre desenvolvimento da personalidade é aquele que pretende reconhecer e proteger as condições para que os sujeitos possam desenvolver sua identidade e se autorrealizarem por intermédio dela.
} 


\section{A moral contra a prostituição}

Há uma justificativa moral e religiosa para a exclusão dos prostituídos da proteção estatal, pois o sexo não é visto como força de trabalho como o trabalho físico ou intelectual. E não seria toda a venda de força de trabalho uma prostituição, ou somente se trabalha por amor, pela necessidade de reprodução? Recorre-se à Lispector (2010, p. 133) para que se faça entender:

Ainda continuo um pouco sem jeito na minha nova função daquilo que não se pode chamar propriamente de crônica. E, além de ser neófita no assunto, também o sou em matéria de escrever para ganhar dinheiro. Já trabalhei na imprensa como profissional, sem assinar. Assinando, porém, fico automaticamente mais pessoal. E sinto-me um pouco como se estivesse vendendo minha alma. É verdade. Mesmo quando não é por dinheiro, a gente se expõe muito. Embora uma amiga médica tenha discordado: argumentou que na sua profissão dá sua alma toda, e no entanto cobra dinheiro porque também precisa viver. Vendo, pois, para vocês com o maior prazer uma certa parte de minha alma - a parte de conversa de sábado.

O olhar negativo que se tem sobre a prostituição decorre da associação de dois pecados capitais, quais sejam, a luxúria e a preguiça. A ideia de que as prostitutas não gostam de trabalhar é transmitida na linguagem coloquial que as alcunha de "mulher de vida fácil". Em razão dessa associação, negam-se a elas e aos demais profissionais do sexo (homens e homossexuais) vários direitos fundamentais, entre os quais os direitos trabalhistas, pois não são vistos como trabalhadores, mas como vagabundos/preguiçosos.

Esses obstáculos de viés moral e religioso são expandidos dos núcleos familiares para os macrossistemas sociais: a escola, o trabalho, a comunidade e a sociedade. Dessa forma, pretende-se verificar se ocorreu, verdadeiramente, em algum paradigma jurídico, a dissolução da tríade direito, moral e religião aclamada pelos estudiosos da Modernidade ou se sempre se precarizou essa dissolução quando o assunto é sexualidade. Os direitos sexuais põem à prova a efetividade dessa dissociação, do desfazimento desse "amálgama normativo" (CARVALHO NETTO, 1997) e escancaram a sua persistência na denominada "pós-modernidade", a qual os autores optam por denominarem contemporaneidade. ${ }^{11}$ A releitura dos direitos de igualdade ${ }^{12}$ e liberdade, ${ }^{13}$ bem como a concepção de essen-

\footnotetext{
11 O significado da preposição pós, segundo o dicionário Silveira Bueno, é: "Após; depois; atrás" (BUENO, 2000, p. 612). Questiona-se: estaríamos, de fato, na pós-modernidade? É possível que se pense em uma sociedade com o elevado nível de exclusão social como a nossa, em que há a necessidade de concretização dos direitos fundamentais, como uma sociedade pós-moderna? Precipitação, conformismo ou pretensão? Por essa razão, opta-se, no presente artigo pela denominação: contemporaneidade ou sociedade contemporânea.

$12 \mathrm{Na}$ obra O direito à igualdade na Constituição Brasileira: comentários ao Estatuto da Igualdade Racial e a constitucionalidade das ações afirmativas na Educação, apresentou-se entendimento acerca do direito de igualdade, amparado pela concepção dworkinana. Assim: "A concepção atual do princípio da igualdade, pautada pelo paradigma do Estado Democrático de Direito, que reconhece a normatividade dos princípios, não se contenta com o seu mero reconhecimento formal, sendo necessário que o Estado e a sociedade, de forma conjunta, envidem todos os esforços para a materialização da igualdade, assegurando-se a todos os indivíduos o direito de participar da vida política da sociedade. Para tanto, deve-se levar em consideração que a igualdade democrática não tem caráter homogeneizante, mas é um direito fundamental que impõe o dever de respeito e consideração pelas diferenças dos indivíduos, em virtude do pluralismo e da complexidade da sociedade contemporânea." (LOBO, 2013, p. 197).

13 "Segundo a igualdade de recursos, os direitos à liberdade que consideramos fundamentais são uma parte ou um aspecto da igualdade distributiva, e estão, portanto, automaticamente protegidos sempre que se alcança a igualdade. A prioridade da liberdade está assegurada, não à custa da igualdade, mas em seu nome." (DWORKIN, 2005, p. 177).
} 
cialidade e correspondência entre eles, necessária à efetivação da dignidade da pessoa humana ao se reconhecer a existência de direitos sexuais, são urgentes para o efetivo desfazimento desse imbróglio.

O direito é produção social, influenciado pelo tempo e pelo espaço, bem como pela cultura, filosofia, política e economia, cujo embasamento atual reside na dignidade da pessoa humana, sendo necessária a revisão da laicidade ${ }^{14}$ estatal para a sua efetividade. O Estado laico é um desafio para que se implementem os direitos humanos, principalmente relacionados à sexualidade e à reprodução. A confusão entre os dois domínios, Estado e religião, importa a negativa à sociedade plural e aberta, convertendo-se o direito em instrumento de força da catequese do credo e moral oficiais. É a negativa da autonomia e a afirmação dos seres humanos como agentes morais. Somente no Estado laico, a liberdade de consciência ganha possibilidade de expressar-se, inclusive como formas de religiosidade ou de seu contrário. Nele, todas as religiões recebem igual consideração e profundo respeito, todas as crenças como crenças têm lugar. Nele, enfim, nem o Estado avança sobre as religiões como superego de uma moral dogmática, nem as religiões avançam nos domínios do Estado como projeto de poder, por exemplo, mediante bancadas religiosas no Legislativo (PIOVESAN, 2008, p. 14).

Não se está aqui a dizer que o direito deva ser cego à moral e à ética, relação de pertinência que deve existir na tensão entre a moralidade plural e a tarefa de pretensa certeza do direito, solucionada de modo dinâmico pela aplicação dos princípios jurídicos no exercício do monopólio estatal da coerção. O que não se deve admitir é a negação ao acesso a direitos fundamentais por uma argumentação religiosa.

Os próprios prostituídos, como vimos, enxergam o exercício de sua atividade como um rito de passagem para uma vida futura mais digna. Assim, a atividade profissional de prostituição também é tida com um meio, sendo excepcionais aquelas situações em que a pessoa enxerga em sua atividade o caráter profissional e reconhece a necessidade da regulação do seu exercício. A afirmação do direito ora reivindicado requer um trabalho reconstrutivo dos princípios informadores do constitucionalismo democrático e da dignidade da pessoa humana para além da mera apuração empírica de vontades.

\section{Direito e moral a favor da prostituição}

A marginalização da prostituição decorre de um discurso moral e religioso de vedação à prática de sexo por prazer ou por necessidade, mas tão somente voltada aos fins da procriação. ${ }^{15}$

\footnotetext{
14 Sampaio (2013, p. 6), ao apresentar a história do Constitucionalismo, apresenta a necessária distinção entre secularização e laicização: "Embora haja um uso indistinto entre secularização e laicização, os dois termos não se equivalem. Ambos se relacionam com a diferenciação moderna entre a esfera público-estatal e religiosa. A secularização se refere mais diretamente à perda de importância social e política do sistema de valores, das instituições e práticas religiosas. É mais um fenômeno social e cultural que político. Secular é o que não é religioso, é o dessacralizado e o profano, submetido às regras da razão. Significava originariamente o processo de expropriação dos bens eclesiásticos pelos príncipes protestantes, seguindo-se, historicamente, pela separação entre igreja e Estado, bem como pela perda do monopólio religioso da educação pública. Laicidade é a qualidade do Estado que afasta a religião de seus domínios e da esfera pública em geral. Trata-se de uma concepção mais política que social. Não importa, todavia, a negação do religioso na esfera privada, impondo, bem ao contrário, a neutralidade ou imparcialidade em relação às orientações religiosa."

15 "Várias vezes ouvimos nos depoimentos que o dinheiro da prostituição não dura porque é amaldiçoado. Esta frase, muitas vezes repetida, tem um importante significado simbólico. A verdade é que não é o dinheiro que é amaldiçoado. A maldição está nas mentes e mãos das prostitutas. É uma maldição social e psicológica que acaba por tornar suas vidas caóticas, impedin-
} 
Os pregadores da Reforma Católica demonizaram a utilização dos órgãos sexuais para outros fins que não a procriação, subsistindo na doutrina católica essa concepção expressa na condenação ao homossexualismo, ao aborto, aos métodos anticoncepcionais e à prostituição. Esse pensamento é paralisador do direito à liberdade de disposição do próprio corpo e do próprio sentido de autonomia. De maneira geral, as religiões (e, consequentemente, os fiéis-eleitores e os fiéis-juízes) são grandes obstáculos a serem transpostos para que se avance na proteção à liberdade sexual e à igualdade advinda desse reconhecimento (D’CUNHA, 1992). ${ }^{16}$ Entretanto, mesmo após o desenvolvimento e o avanço da medicina contraceptiva, em um claro reflexo à liberdade sexual conquistada, sobretudo na década de 1960, bem como com a viabilização da discussão aberta sobre práticas sexuais e homossexuais, a exploração comercial da libido feminina por meio de produtos eróticos e literatura erótica, ${ }^{17}$ e a autodeclaração comportamental como "vadia" em marchas, em resposta à violência sexual, persiste o tabu relativamente à prostituição. Essa repugnância justifica, ainda que veladamente, a violência praticada contra essas profissionais.

Não se lhes toma somente a dignidade relativa à possibilidade de se reconhecerem como trabalhadores, ${ }^{18}$ mas a própria dignidade de ser pessoa, de ser humano, cuja integridade corporal deve ser resguardada e protegida. Vê-se uma confusão social entre a liberdade de disposição do próprio corpo, mediante a livre iniciativa e venda da força de trabalho (como toda e qualquer profissão, seja o trabalho prevalentemente físico, seja intelectual, a ser, portanto, tratado em seu processo de alienação de mão de obra), e o respeito à integridade corporal dessas pessoas: "Joga pedra na Geni! Joga bosta na Geni! Ela é feita pra apanhar! Ela é boa de cuspir! Ela dá pra qualquer um! Maldita Geni!" (BUARQUE, 1978).

\footnotetext{
do com isso, que guardem o dinheiro que conseguem. Para organizar a vida é essencial parar o trânsito contínuo, é necessário criar vínculos com pessoas e lugares. Mas, prisioneiras da liminaridade, elas correm sem rumo para chegar a lugar nenhum, ou melhor, para chegar à morte. É por isso que prostituta morre cedo, como nos disseram várias entrevistadas." (MÉIS, 2010, p. 240).

16 Para se assegurar a efetividade da igualdade no Estado Democrático não se pode ter em mente a ideia de princípio majoritário. É essencial à realização da democracia constitucional a contramajoritariedade. "Se rejeitarmos a premissa majoritária, precisaremos de uma explicação diferente, e melhor, do valor e da finalidade da democracia. Vou defender agora uma explicação - que chamo de concepção constitucional de democracia - que efetivamente rejeita a premissa majoritária. Segundo essa explicação, o fato de as decisões coletivas serem sempre, ou normalmente, as decisões que a maioria dos cidadãos tomaria se fossem plenamente informados e racionais não é nem uma meta nem uma definição da democracia. O objetivo que define a democracia tem de ser diferente: que as decisões coletivas sejam tomadas por instituições políticas cuja estrutura, composição e modo de operação dediquem a todos os membros da comunidade, enquanto indivíduos, a mesma consideração e o mesmo respeito. É certo que essa explicação alternativa do objetivo da democracia exige uma estrutura de Estado muito semelhante à exigida pela premissa majoritária. Exige que as decisões políticas do dia-a-dia sejam tomadas por agentes políticos escolhidos nas eleições populares. Porém, a concepção constitucional requer esses procedimentos majoritários em virtude de uma preocupação com a igualdade dos cidadãos, e não por causa de um compromisso com as metas da soberania da maioria. Por isso, não opõe objeção alguma ao emprego deste ou daquele procedimento não-majoritário em ocasiões especiais nas quais tal procedimento poderia proteger ou promover a igualdade que, segundo essa concepção, é a própria essência da democracia; e não aceita que essas exceções sejam causa de arrependimento moral." (DWORKIN, 2006, p. 26).

17 "O desejo se concentra, sombrio e mortal, em minha virilha. Ele aperta minha mão, roça meus dedos com o polegar, e, dentro de mim, todos os músculos se enrijecem deliciosamente." (JAMES, 2012, p. 20). E. L. James, com o casal Anastasia Steele e Christian Grey "glamourizou" a literatura erótica das prostitutas e ascensoristas no romance "sadô-masô" Cinquenta tons de cinza, trilogia bestseller merchandising (Apple, Blackberry, Audi), que demonstrou a necessidade das mulheres de falarem e ouvirem sobre sexo, bem como receberem uns "presentinhos" do amado para a melhoria do desempenho sexual, sem que, com isso, sejam consideradas prostitutas, é claro!

18 Veja-se, por exemplo, a dignidade projetada no direito à profissão e ao trabalho em Wax (2003, p. 101-115).
} 
Pode-se dizer que a regulação da prostituição possui a possibilidade de se reconhecer socialmente (de maneira formal, sendo necessária a mudança cultural da mentalidade) a dignidade dos profissionais do sexo, mediante um tratamento igualitário ao dispensado aos demais trabalhadores, com a mesma consideração e respeito, viabilizando o reconhecimento dessas pessoas também como fim em si mesmo, ainda que o exercício da atividade seja visto por elas próprias como algo passageiro (meio) em suas vidas.

São várias as consequências sociais da regulação da atividade da prostituição para além de uma preocupação tão somente com o reconhecimento dos direitos trabalhistas, quais sejam: a possibilidade de redução da criminalidade que decorre do contexto marginal em que vivem os prostituídos, associados a crimes, como, por exemplo, o tráfico de drogas e a cafetinagem; a discussão aberta sobre prostituição e saúde pública, por meio de atividades de prevenção de DSTs, bem como o debate e a possibilidade de descriminalização do aborto; a tributação da prestação de serviços de prostituição; e aspectos previdenciários do profissional do sexo.

A regulação do exercício da atividade implicará também restrições ao exercício da prostituição, por exemplo, com a determinação de serem observadas normas de vigilância sanitária, inclusive mediante a utilização obrigatória de preservativos ou estar com alguma vacina em situação de regularidade.

Não se pode admitir a persistência desse tipo de discriminação, pois se apresenta como vilipêndio à dignidade da pessoa humana. ${ }^{19}$ Em alguns países do mundo, por exemplo, na Holanda, a legislação vem avançando no reconhecimento de direitos aos profissionais do sexo. Entretanto, há retrocessos que também ganham destaque e força, por exemplo, a aprovação pela França de lei que visa à punição de clientes que se utilizarem dos serviços de prostituição. ${ }^{20}$

\section{A prostituição no direito comparado}

O direito comparado revela um quadro heterogêneo no reconhecimento do trabalho do profissional do sexo; este reconhecimento bem como a descriminalização de sua prática caracterizam a análise do direito comparado. Em geral, é tratada no âmbito da licitude com ou sem regulamentação, ou no plano da ilicitude (BANACH; METZENRATH, 2000; BARNETT, CASAVANT, NICOL, 2011). Na Nova Zelândia, por exemplo, é uma atividade lícita, um trabalho como outro, sem necessidade de regulamentação específica. A licitude regulada aparece, por exemplo, na Alemanha, na Austrália, na Áustria, em alguns condados rurais do Estado de Nevada nos Estados Unidos, na Grécia, na Holanda, na Hungria, na Suíça, na Tunísia e na Turquia, podendo ser muito invasiva ou disciplinada, como em Nevada, ou sem maiores rigores ou exigências como na Holanda.

\footnotetext{
19 Não se está aqui a tratar da discriminação sexista no mercado do trabalho de todos já conhecida, segundo a qual as mulheres recebem piores salários, não alcançam cargos de chefia ou enfrentam de maneira muito mais árdua os obstáculos impostos pelo mercado de trabalho, em decorrência da maternidade. Gravíssima e que também merece atenção dos estudiosos. Aqui se trata de inacessibilidade, impossibilidade de exercício, vedação. Não há regras, não há jogo. São as famosas "cartas fora do baralho".

20 E lá se vão os tempos majestosos de Moulin Rouge, o famoso cabaré, retratado no musical homônimo protagonizado por Nicole Kidman, a prostituta Satine.
} 
A ilicitude comporta graus, tendendo-se a uma zona gris entre a licitude, nos modelos abolicionistas e, em menor extensão, nos neoabolicionistas, até chegar ao proibicionismo (CHUANG, 2010). No primeiro modelo, abolicionista, a atividade não é ilícita, mas é considerada um problema social que deve ser enfrentado por políticas públicas e criminais que impeçam ou punam sua facilitação ou encorajamento. Punem-se, assim, o rufianismo e a casa de prostituição. É adotado em países como Canadá, França, Polônia, Portugal e Reino Unido. Por vezes, tolera-se a prática da prostituição, mas sem reconhecê-la como trabalho ou profissão. Ocorre, assim, no Brasil, na Espanha e na Bélgica - este último analisa projeto de lei para regulação. Na América Latina, as casas de prostituição são descriminalizadas e reguladas no México, Bolívia, Colômbia, Equador, Paraguai, Peru, Uruguai e Venezuela (VIANNA, 2012).

Os neoabolicionistas enxergam na atividade uma forma de violência contra os direitos humanos da mulher. Não se pune a prostituta, mas os seus clientes. É como sucede na Islândia, Noruega e Suécia (FARLEY, 2004).

O proibicionismo criminaliza quem vende ou compra o corpo. São proibicionistas, alguns adotando punições capitais, a Arábia Saudita, Belize, Birmânia, China, Coreia do Sul, Egito, Emirados Árabes Unidos, Filipinas, Iêmen, Irã, Laos, Letônia, Marrocos, Mongólia, Nepal, Sri Lanka e Vietnã. É também a orientação seguida pelos Estados Unidos, excepcionados alguns condados de Nevada. Merece registro, todavia, a decisão da Suprema Corte do país que, em junho de 2011, afastou a cláusula antiprostituição estabelecida como requisito para que entidades fossem beneficiadas com programas de financiamento para a prevenção e o combate da AIDS pela The United States President's Emergency Plan for Aids Relief (PEPFAR) (ESTADOS UNIDOS, 2011).

\section{A prostituição no direito brasileiro}

No Brasil, o reconhecimento da importância econômica da atividade de prostituição se manifestou pela possibilidade de pagamento desse serviço com cartão de crédito, o que foi viabilizado pela Caixa Econômica Federal em uma parceria com a Associação das Prostitutas de Minas Gerais (Aspromig) a partir de novembro de 2013. Esse tipo de ação demonstra a união (ainda tímida) desses profissionais visando ao reconhecimento de iguais direitos relativos à liberdade de iniciativa e à valorização do trabalho humano. Outras ações também são organizadas pela associação, como, por exemplo, o "Puta Dei", evento que ocorre no dia internacional da prostituta, dia 02 de junho, ocasião em que manifestam, sobretudo, pela não criminalização.

É um passo importante, mas ainda é muito pouco. Historicamente, o Legislativo tem se mostrado pouco sensível às causas sociais dos excluídos, principalmente se a temática é moral e religiosamente condenável, diante da possibilidade de "abalo" da imagem dos políticos que levantam a bandeira ou se manifestam a ela favoráveis. A invisibilidade política é retratada por Dworkin (2006, p. 656):

Em primeiro lugar, o grupo pode ser tão marginalizado financeira, social e politicamente, que lhe faltem meios para chamar a atenção dos políticos e dos outros eleitores para seus interesses e, assim, não exercer o poder nas urnas, ou em alianças ou barganhas com outros grupos, que se esperaria que o número de componentes 
do grupo fosse capaz de produzir. Em segundo lugar, pode ser vítima de vieses, preconceitos, ódios ou estereótipos tão graves que a maioria queira reprimi-lo ou puni-lo por tal motivo, mesmo quando as punições não sirvam a nenhum outro interesse, mais respeitável ou legítimo, de outros grupos.

No Legislativo federal, o Projeto de Lei n. 98/2003, elaborado pelo deputado Fernando Gabeira, visando à regulação da prostituição, foi arquivado. A maior justificativa para a rejeição do Projeto de Lei residiu na inobservância à moralidade, manifestada pelos Deputados Paulo Maluf e ACM Neto. ${ }^{21}$

Em 12 de julho de 2012 foi apresentado na Câmara dos Deputados o Projeto de Lei n. 4.211/2012, de autoria do Deputado Federal Jean Wyllys, que visa à regulação da atividade dos profissionais do sexo de forma autônoma ou coletiva, por cooperativas - Lei Gabriela Leite, que se fundamenta na Lei alemã que regulamenta as relações jurídicas das prostitutas (Gesetz zur Regelung der Rechtsverhältnisse der Prostituierten - Prostitutionsgesetz - ProstG). A Comissão de Direitos Humanos e Minorias da Câmara dos Deputados, sob a relatoria do Deputado Pastor Eurico (PSB-PE), rejeitou o referido Projeto de lei, fundamentando a rejeição em diversos argumentos, sendo necessário destacar aquele segundo o qual não há tolerância da prostituição em qualquer passagem do Novo Testamento. ${ }^{22}$

No Judiciário, é escasso o enfrentamento do tema, sendo de grande relevância a sentença proferida pelo juiz da $2^{\text {a }}$ Vara Criminal de São Gonçalo, RJ, André Luiz Nicolitt, nos autos do processo n. 0056213-63.2010.8.19.0004, no qual o magistrado, analisando denúncia do crime de formação de quadrilha (artigo 288 do Código Penal) pela suposta exploração sexual de mulheres adultas, cujo objeto seria a venda do sexo, absolveu os réus, por entender que a casa de prostituição é uma conduta social aceita pela sociedade, e, em não havendo tráfico de pessoas ou exploração sexual de menores, não configuraria a conduta tipificada como formação de quadrilha. Fundamentou o juiz a sua decisão utilizando-se do princípio da secularização, sob o argumento de que "[...] o moderno direito penal não pode considerar crimes condutas que mais se aproximam de pecado." (RIO DE JANEIRO, 2011).

\footnotetext{
$\overline{21}$ ACM Neto, relator da Comissão de Constituição e Justiça e de Cidadania à época da análise do Projeto de Lei n. 98/2003, afirmou em seu parecer que um contrato "[...] cujo objeto seria o comércio do próprio corpo para fins libidinosos não estaria em sintonia com o sistema." Utilizou, ainda, o parlamentar a seguinte justificativa: "Mais importante é evitar que jovens, sobretudo das classes menos favorecidas, sejam levadas a prostituir-se como única opção para auferir algum ganho. $\bigcirc$ que falta são políticas públicas voltadas à geração de emprego, para que as jovens do nosso País, muitas com bom nível de escolaridade, possam desempenhar atividades produtivas e socialmente justas, livrando-se da praga da prostituição (CÂMARA DOS DEPUTADOS, 2003, grifo nosso). A expressão do relator converge com a maioria da opinião pública acerca da "praga" que é a prostituição. Mais uma manifestação que demonstra que, para além da alteração quantitativa, segundo a qual bastaria a aprovação do projeto de lei e regulação da prostituição, é necessária a alteração estrutural, cultural (qualitativa, conforme reflexões propostas pela Professora Marinella Machado de Araújo quando da exposição desta pesquisa na Critical Legal Conference - 2014, na Universidade de Sussex, em Brighton, Inglaterra) da sociedade brasileira para aceitação de modelos de vida diversos dos "moralmente dominantes", daqueles considerados "normais" para os padrões sexuais religiosos e monogâmicos. 22 Relator da Comissão de Direitos Humanos e Minorias, o Deputado Federal Pastor Eurico rejeitou o Projeto de Lei n. 4.211/2012. Em seu voto, afirmou: "Também tem sido lugar comum, mesmo entre ateus, citar passagem bíblica em que Jesus defende uma prostituta da morte por apedrejamento como justificativa para apoiar a prostituição. Trata-se de uma leitura totalmente descontextualizada da Bíblia. Jesus defende a pessoa que cometeu o pecado mas não a prostituição, dizendo: 'Aquele que dentre vós estiver sem pecado seja o primeiro que lhe atire pedra.' Depois disse para a adúltera: 'vai-te e não peques mais.' Aliás, a suposta tolerância diante da prostituição não existe nessa ou em qualquer passagem do Novo Testamento." (CÂMARA DOS DEPUTADOS, 2012).
} 
No âmbito da especializada trabalhista, o Tribunal Superior do Trabalho, em 2013 (BRASIL, 2013b), entendeu pela existência de vínculo empregatício entre garçom e casa de prostituição. Contudo, não há decisão judicial que envolva o reconhecimento do exercício do trabalho de prostituição tout court.

\section{Conclusão}

O profissional do sexo é objeto e não sujeito de direito, pela negativa do seu direito fundamental ao trabalho. Sua dignidade é relativizada, senão negada. A possibilidade de regulação da prostituição, sob a óptica do Direito Constitucional contemporâneo, funda-se no resgate dessa dignidade excluída e no pressuposto democrático constitucional, que impõem a todos igual respeito e consideração, inclusive e principalmente contra a vontade empírica da maioria.

A Constituição se apresenta como possibilidade, não como um dado, mas como um construído, por meio de ações jurídicas e políticas que concretizam os direitos fundamentais, ainda que contramajoritariamente, no presente caso, mediante o reconhecimento da igualdade e DA liberdade dos profissionais do sexo.

A Constituição como elemento que apazigua, mas também como fonte de tensão no âmbito de uma sociedade plural, deve ser instrumento emancipatório de grupos sociais marginalizados, não se fechando ao dissenso. Somente assim possibilita a efervescência participativa militante social, política e acadêmica para a efetividade dos direitos fundamentais. $\mathrm{O}$ convite à reflexão agora se faz: "Won't you help too sing/ these songs of freedom/ 'Cause all I ever had/Redemption songs/ Redemption songs." (MARLEY, 1984).

\section{Referências}

ALENCAR, José de. Luciola. 26. ed. São Paulo: Ática, 1999.

ALVARENGA, Rúbia Zanotelli de. O direito do trabalho como dimensão dos direitos humanos. São Paulo: LTr, 2009.

AQUINAS, Thomas. Summa Theologica. Chicago: Encyclopaedia Brittanica, 1978.

BACKER, Larry C. Theocratic Constitutionalism: an introduction to a new global legal ordering. Indiana Journal of Global Legal Studies, v. 16, n. 85, p. 101-181, 2009.

BAEZ, Narciso Leandro Xavier; SILVA, Rogério Luiz Nery da; SMORTO, Guido (Org.). Os desafios dos direitos humanos fundamentais na América Latina e na Europa. Joaçaba: Ed. Unoesc, 2012.

BANACH, Linda; METZENRATH, Sue. Principles for Model Sex Industry Legislation. In: SULLIVAN, M. (Ed.). Making Sex Work - A failed Experiment with legalised Prostitution. Melbourne: Spinifex Press, 2000. 
BARCELLOS, Ana Paula de; BARROSO, Luis Roberto. O começo da história. A nova interpretação constitucional e o papel dos princípios no Direito brasileiro. In: SAMPAIO, José Adércio Leite (Coord.). Crise e desafios da constituição: perspectivas críticas da teoria e das práticas constitucionais brasileiras. Belo Horizonte: Del Rey, 2003.

BARNETT, Laura; CASAVANT, Lyne; NICOL, Julia. Prostitution: a review of legislation in selected countries. Ottawa: Library of Parliament, 2011.

BARROSO, Luís Roberto. Curso de Direito Constitucional Contemporâneo: os conceitos fundamentais e a construção do novo modelo. 3. ed. São Paulo: Saraiva, 2011.

BASSERMANN, Lujo. The oldest profession: a history of prostitution. New York: Dorset House Publishing Co Inc., 1994.

BELCHIOR. Alucinação. Intérprete Belchior. 20 Músicas do Século XX. São Paulo: Polygram, 1989.

BÍBLIA ON. Lucas 8:2. Disponível em: <http://www.bibliaon.com/versiculo/lucas_8_2/>. Acesso em: 31 maio 2014.

BRASIL. Constituição. República Federativa do Brasil de 1988. Brasília, DF: Senado Federal, 1988. Disponível em: <http://www.planalto.gov.br/ccivil_03/Constituicao/Constituiçao.htm>. Acesso em: 11 jan. 2014.

BRASIL. Supremo Tribunal Federal. Pleno. Arguição de Descumprimento de Preceito Fundamental n. $54 /$ DF. Relator: Ministro Marco Aurélio. Publicado em 30 abr. 2013a. Disponível em: <http://www. stf.jus.br/portal/processo/verProcessoAndamento.asp?incidente $=2226954>$. Acesso em: 03 fev. 2014.

BRASIL. Supremo Tribunal Federal. Pleno. Recurso Extraordinário n. 477.554/MG. Relator: Ministro Celso de Mello. Publicado em 26 ago. 2011. Disponível em: <http://www.stf.jus.br/portal/processo/verProcessoAndamento.asp?incidente=2376061 > . Acesso em: 27 maio 2012.

BRASIL. Tribunal Superior do Trabalho. Agravo Regimental em Agravo de Instrumento de Recurso de Revista n. 955-43.2010.5.10.0821. Relatora: Desembargadora Convocada Maria das Graças Silvany Dourado Laranjeira. $2^{\text {a }}$ Turma. Julgamento em 27 maio 2013. DEJT, 31 maio 2013b. Disponível em: <https://aplicacao5.tst.jus.br/consultaProcessual/resumoForm.do?consulta=1\&numerolnt=158131\&anoInt=2011 > . Acesso em: 30 jan. 2014.

BROWN, Dan. O Código da Vinci. São Paulo: Sextante, 2004.

BUARQUE, Chico. Geni e o Zepelin. Intérprete Chico Buarque. In: BUARQUE, Chico. Ópera do Malandro (Org.). Rio de Janeiro: Universal, 1978.

BUENO, Silveira. Silveira Bueno: minidicionário da língua portuguesa. São Paulo: FTD, 2000.

CÂMARA DOS DEPUTADOS. Projeto de Lei n. 98/2003. Parecer do Relator Antônio Carlos Magalhães Neto. Disponível em: <http://www.camara.gov.br/proposicoesWeb/fichadetramitacao?idProposicao $=286394>$. Acesso em: 29 set. 2014.

CÂMARA DOS DEPUTADOS. Projeto de Lei n. 4.211/2012. Voto do Relator da Comissão de Direitos Humanos e Minorias - Deputado Pastor Eurico. Disponível em: <http://www.camara.gov.br/ proposicoesWeb/prop_mostrarintegra?codteor=1012829>. Acesso em: 03 fev. 2014. 
CARVALHO NETTO, Menelick de. Requisitos pragmáticos da interpretação jurídica sob o paradigma do Estado Democrático de Direito. Revista de Direito Comparado, Belo Horizonte: Mandamentos, v. 3, p. 473-486. 1997.

CHUANG, Janie A. Rescuing trafficking from ideological capture: prostitution reform and anti-trafficking law and policy. University of Pennsylvania Law Review, v. 158, i. 6, 2010, p. 1655-1728.

CÍCERO. De Officiis. Tradução W. Miller. London: Woods and Sons, 1913. Disponível em: <http:// bit.ly/1nVS7FA>. Acesso em: 12 set. 2014.

COMPLAK, Krystian. Cinco teses sobre a dignidade da pessoa humana como conceito jurídico. Revista da ESMEC, v. 15, n. 21, 2008. Disponível em: <http://www.esmesc.com.br/upload/arquivos/4-1246972961.PDF>. Acesso em: 20 jun. 2013.

CRUZ, Álvaro Ricardo de Souza. Jurisdição Constitucional Democrática. Belo Horizonte: Del Rey, 2004.

CRUZ, Álvaro Ricardo de Souza. O direito à diferença: ações afirmativas como mecanismo de inclusão social de mulheres, negros, homossexuais e pessoas portadoras de deficiência. 2. ed. Belo Horizonte: Del Rey, 2005.

CRUZ, Álvaro Ricardo de Souza. Processo Constitucional e a efetividade dos Direitos Fundamentais. In: SAMPAIO, José Adércio Leite; CRUZ, Álvaro Ricardo de Souza (Coord.). Hermenêutica e Jurisdição Constitucional. Belo Horizonte: Del Rey, 2001. p. 195-248.

DAVIDSON, Julia O'Connel. The rights and wrongs of prostitution. Hypatia, v. 17, i. 2. 2002. Disponível em: <http://wrightjj1.people.cofc.edu/teaching/PHIL3000/rights\%20wrongs\%20of\%20 prostitution.pdf >. Acesso: 30 jan. 2014.

D'CUNHA, Jean. Prostitution laws: ideological dimensions and enforcement practices. Economic and Political Weekly, v. 27, p. 34-44, 1992.

DEL PRIORE, Mary. Sexualidade e Erotismo na História do Brasil. São Paulo: Planeta do Brasil, 2011.

DWORKIN, Ronald. A virtude soberana: a teoria e a prática da igualdade. Tradução Jussara Simões. São Paulo: Martins Fontes, 2005.

DWORKIN, Ronald. O direito da liberdade: a leitura moral da Constituição. Tradução Marcelo Brandão. São Paulo: Martins Fontes, 2006.

ESTADOS UNIDOS. Government interagency website managed by the Office of U.S. Global AIDS Coordinator and the Bureau of Public Affairs, U.S. State Department. 2011. Disponível em: <http://www. pepfar.gov/about/index.htm>. Acesso em: 09 dez. 2016.

FARLEY, Melissa "Bad for the body, bad for the heart": prostitution harms women even if legalized or decriminal-ized". Violence against Women, 2004, v. 10, i. 10, p. 1087-1125, 2004.

GALUPPO, Marcelo Campos. Hermenêutica Constitucional e Pluralismo. In: SAMPAIO, José Adércio Leite; CRUZ, Álvaro Ricardo de Souza (Coord.). Hermenêutica e Jurisdição Constitucional. Belo Horizonte: Del Rey, 2001. p. 47-64. 
GALUPPO, Marcelo Campos. Igualdade e diferença: Estado democrático de direito a partir do pensamento de Habermas. Belo Horizonte: Mandamentos, 2002.

HABERMAS, Jürgen. A Inclusão do Outro: estudos de teoria política. São Paulo: Edições Loyola, 2002.

HOBBES, Thomas. Leviathan. Tradução R. Tuck. Cambridge: Cambridge University Press, 2002.

JAMES, E. L. Cinquenta tons mais escuros. Rio de Janeiro: Instrínseca, 2012.

KANT, Immanuel. Critique of Practical Reason. [S.1.]: Bibliotech Press, 2014.

KANT, Immanuel. Groundwork of the Metaphysics of Morals. Tradução Mary J. Gregor. Cambridge; New York: Cambridge University Press, 1997.

KRIEGER, Mariana Gusso. O direito fundamental ao trabalho e sua (estreita) relação com o direito ao livre desenvolvimento da personalidade. Revista Fórum Trabalhista: RFT, Belo Horizonte: Fórum, ano 1, n. 1, mar./abr. 2012.

LANDA, Cesar. "Dignidade de la Persona Humana”. Cuestiones, n. 7, p. 109-138, jul./dic. 2002.

LELIS, Davi Augusto Santana de Lelis. Uma teoria do interesse público. IN: GUERRA, Roberta Freitas; SILVA, Fernando Laércio Alves da; NERO, Patrícia Aurélia Del (Org.). Neoconstitucionalismo em perspectiva. Viçosa: Ed. UFV, 2014.

LISPECTOR, Clarice. Clarice na cabeceira: crônicas. Rio de Janeiro: Rocco, 2010.

LOBO, Bárbara Natália Lages. O direito à igualdade na Constituição Brasileira: comentários ao Estatuto da Igualdade Racial e a constitucionalidade das ações afirmativas na educação. Belo Horizonte: Fórum, 2013.

LUHMANN, Niklas. Diritti Fondamentali come Istituzione. Tradução Stefano Magnolo. Bari: Edizioni Dedalo, 2002.

MARCEL, Gabriel. La Dignité Humaine et ses Assises Existentielles. Paris: Aubier, Éditions Montaigne, 1964.

MARLEY, Bob. Redemption song. Intérpretes Bob Marley \& The Wailers. Legend. Jamaica: Tuff Gong Records, 1984.

MCCRUDDEN, Christopher. Human dignity and judicial interpretation of human rights. European Journal of Internationl Law, v. 19, p. 655-724, 2008.

MÉIS, Carla. Prostituição e marginalidade: narrativas de identidade entre prostitutas. In: RENAULT, Luiz Otávio Linhares; VIANA, Márcio Túlio; CANTELLI, Paula Oliveira (Coord.). Discriminação. 2. ed. São Paulo: LTr, 2010.

MIRANDOLA, Giovanni Pico Della. On the Dignity of Man (De hominis dignitate, Heptaplus, De ente et uno, e scritti vari). Tradução Charles Glenn Wallis. Indianapolis: The Bobbs-Merrill Company, Inc., 1965. 
MOREIRA, Ariágda dos Santos. O espaço da prostituta na literatura brasileira do séc. XX. Belo Horizonte: Ed. UFMG, 2007. Disponível em: <http://periodicos.letras.ufmg.br/index.php/caligrama/ article/viewFile/190/142>. Acesso em: 03 de fev. 2014.

MOTA, Marcel Moraes. Pós-positivismo e restrições de direitos fundamentais. Fortaleza: Omni, 2006.

MURPHY, Walter F. An Ordering of Constitutional Values. Southern California Law Review, v. 53, p. 703-760, 1980.

NASSIF, Luis. As leis sobre prostituição em diversos países europeus. Jornal GGN, 09 dez. 2013. Disponível em: <http://jornalggn.com.br/noticia/as-leis-sobre-prostituicao-em-diversos-paises-europeus>. Acesso em: 01 jan. 2014.

NOVAIS, Jorge Reis. Direitos Fundamentais: trunfos contra a maioria. Coimbra: Coimbra Editora, 2006.

OLIVAR, José Miguel Nieto. O direito humano de ser puta: uma reflexão sobre direitos sexuais no universo da prostituição feminina em Porto Alegre. Teoria e Sociedade, n. 15, n. 2, jul./dez. 2007. Disponível em: <http://mysql.fafich.ufmg.br/ revistasociedade/edicoes/artigos/15_2/O_DIREITO_HUMANO_DE_SER_PUTA.pdf>. Acesso em: 03 fev. 2014.

PIOVESAN, Flávia. Concepção contemporânea de direitos humanos: desafios e perspectivas. In: ROCHA, João Carlos de Carvalho; HENRIQUES FILHO, Tarcísio Humberto Parreiras; CAZETTA, Ubiratan (Org.). Direitos humanos: desafios humanitários contemporâneos: 10 anos do Estatuto dos Refugiados (Lei n. 9274 de 22 de julho de 1997). Belo Horizonte: Del Rey, 2008.

PONTIFÍCIA UNIVERSIDADE CATÓLICA DE MINAS GERAIS. Pró-Reitoria de Graduação. Sistema de Bibliotecas. Padrão PUC Minas de normalização: normas da ABNT para apresentação de trabalhos científicos, teses, dissertações e monografias. Belo Horizonte, 2010. Disponível em: <http://www.pucminas.br/ biblioteca >. Acesso em: 03 fev. 2014.

RACHELS, James. The Elements of Moral Philosophy. Boston: Random House, Inc., 1986.

RIO DE JANEIRO (Estado). Tribunal de Justiça. Processo n. 0056213-63.2010.8.19.0004. Relator: Juiz André Luiz Nicolitt. $2^{a}$ Vara Criminal de São Gonçalo. Publicado em 06 abr. 2011. Disponível em: <http://www.tjrj.jus.br/documents/10136/624857/boletim-do-servico-de-difusao-80-11.pdf>. Acesso em: 03 fev. 2014.

SAMPAIO, José Adércio Leite. Direitos Fundamentais: retórica e historicidade. Belo Horizonte: Del Rey, 2004.

SAMPAIO, José Adércio Leite. Introdução e Bricolagem sobre Constituição e Crise Política. In: SAMPAIO, José Adércio Leite (Coord.). Constituição e Crise Política. Belo Horizonte: Del Rey, 2006.

SAMPAIO, José Adércio Leite. Teoria da Constituição e dos Direitos Fundamentais. Belo Horizonte: Del Rey, 2013.

SARAMAGO, José. O Evangelho segundo Jesus Cristo. São Paulo: Companhia das Letras, 1991.

SARLET, Ingo W. A eficácia dos direitos fundamentais. 11. ed. Porto Alegre: Livraria do Advogado, 2012. 
SCHOOYANS, Michel. "Dignidade de la Persona Humana, Principio Básico de la Doctrina Social de la Iglesia". In: LÓPEZ, Teodoro et al (Org.). Centenario de la "Rerum novarum". In: SIMPOSIO INTERNACIONAL DE TEOLOGÍA DE LA UNIVERSIDAD DE NAVARRA, 12., 1991, Navarra. Anais... Navarra: EUNSA, 1991.

SOUZA, Jessé. A ralé brasileira: quem é e como vive. Belo horizonte: Ed. UFMG, 2009.

VIANNA, Túlio. Legalizar as casas de prostituição. Revista Fórum, 09 fev. 2012. Disponível em: < http://revistaforum.com.br/blog/2012/02/legalizar-as-casas-de-prostituicao/>. Acesso em: 03 fev. 2014.

VIOLA, Francesco. "I Volti della Dignità Umana". In: ARGIROFFI, Alessandro; BECCHI, Paolo, ANSELMO, Daniele (a cura di). Colloqui sulla Dignità Umana. Atti del Convegno Internazionale, Parlemo, Ottobre, 2007. Roma: Aracne, 2008.

VIORST, Judith. Perdas necessárias. Tradução Aulyde Soares Rodrigues. 4. ed. São Paulo: Melhoramentos, 2005.

WAX, Amy L. "Social Welfare, Human Dignity, and the Puzzle of What We Owe Each Other". Harvard Journal of Law \& Pubic Policy, v. 27, p. 101-115, 2003.

Data da submissão: 07 de junho de 2016 Avaliado em: 01 de agosto de 2016 (AVALIADOR A) Avaliado em: 24 de julho de 2016 (AVALIADOR B) Aceito em: 04 de novembro de 2016 
